\title{
Graft Copolymerization onto Cellulose Derivatives. IV. Graft Copolymerization of Styrene and Styrene-Methyl Methacrylate onto Cellulosic Materials Containing Carbonyl and Carboxyl Groups
}

\author{
Akira TAKAhaShI and Shirō TAKAhaShI \\ Kogakuin University, Shinjuku-ku, Tokyo, Japan.
}

(Received June 26, 1973)

\begin{abstract}
The graft copolymerization of styrene ( $\mathrm{St}$ ) and styrene+methyl methacrylate (MMA) on to cellulosic materials containing carbonyl and carboxyl groups was carried out using ceric salt as an initiator.

Graft copolymerization of styrene: The percent grafting reached a maximum or a levelling-off value at a ceric salt concentration of approximately $10-20 \mathrm{mmol} / l$, and the values varied with ethanol concentration in the polymerization medium. The percent grafting of styrene onto cellulosic materials increased with the carbonyl group content and decreased with increasing carboxyl group. The apparent activation energy calculated from the initial rate of graft copolymerization was approximately $14.2 \mathrm{kcal} / \mathrm{mol}$. From these results it is deduced that the graft copolymerization is initiated by the redox reaction between the ceric salt and the carbonyl group and the catalytic activity of the initiator decreased due to the reaction between the ceric salt and the carboxyl group.

Graft copolymerization of styrene-methyl methacrylate: Total conversion and percent grafting increased with the methyl methacrylate content in the feed, and the polymerization rate was greatly enhanced by the presence of cellulosic materials. The copolymerization of these monomers proceeds by a free radical mechanism. The monomer reactivity ratios $r_{1}$ (MMA) and $r_{2}$ (St) of grafted and ungrafted copolymers were determined by using the Fineman-Ross method.

From these results, it is considered that the monomer reactivity ratio of copolymer obtained by the copolymerization in the presence of cellulosic materials are different to those carried out in the absence of cellulosic materials. This is due to the interaction between the cellulosic materials and the monomers.

KEY WORDS Polymerization / Styrene / Styrene-Methyl Methacrylate / Cellulose / Functional Group / Ceric Ion / Rate / Alternating Tendency /
\end{abstract}

A number of papers have appeared on the graft copolymerization of vinyl monomers on to cellulose, but little has been published on cellulosic materials containing carbonyl and carboxyl groups. ${ }^{1,2}$ We have studied the graft copolymerization of various vinyl monomers on to cellulosic materials which contain different amounts of carbonyl and/or carboxyl groups. Some interesting results were obtained.

In the present paper, we report on the effects of initiator, solvent, monomer concentration, temperature and amount of functional groups on the graft copolymerization of styrene on to periodate-oxidized cellulose and its derivatives.

This paper also refers to the graft copolymerization of styrene and methyl methacrylate on to the cellulosic materials and to the alternating tendency in the copolymerization of both grafted and ungrafted copolymers.

\section{EXPERIMENTAL}

Preparation and Analysis of Cellulosic Materials Periodate-oxidized cellulose $(\mathrm{H}$ sample) was prepared by oxidation of cotton linter with $0.05 \mathrm{~mol}$ of sodium metaperiodate aqueous 


\section{A. Takahashi and S. Takahashi}

solution ( $\mathrm{pH} 3.6$ ) at $25^{\circ} \mathrm{C}$ for the required times.

Periodate-chlorous acid treated cellulose $(\mathrm{H}-$ $\mathrm{Na}$ sample) was prepared by the reoxidation of $\mathrm{H}$ sample with $0.2 \mathrm{~mol}$ of sodium chlorous acid containing $1 \mathrm{~mol}$ of acetic acid at $20^{\circ} \mathrm{C}$ for $72 \mathrm{hr}^{3}$

Periodate-borohydride treated cellulose $(\mathrm{H}-\mathrm{B}$ sample) was prepared by reduction of $\mathrm{H}$ sample with $1 \mathrm{~mol}$ of sodium borohydride aqueous solution at $25^{\circ} \mathrm{C}$ for $24 \mathrm{hr}$.

These cellulosic materials are of the same fibrous form of the original sample.

The carboxyl and carbonyl group content in the cellulosic materials used for the graft copolymerization were determined by using the calcium acetate $^{5}$ and semicarbazide ${ }^{6}$ methods, respectively.

\section{Reagents}

Styrene (St) and methyl methacrylate (MMA) were purified by distillation under nitrogen at reduced pressure. Ceric ammonium nitrate (ceric salt) was used as 0.1 -mol aqueous solution.

\section{Polymerization}

Graft copolymerization was carried out in a flask by addition in the order given of: cellulose, water, ethanol, and monomer (St or MMA-St), followed by the ceric salt solution under a nitrogen atomosphere, the solution was then kept at a constant temperature. ${ }^{4}$ The polymer was precipitated by addition of methanol containing hydroquinone, filtered, washed with methanol and dried at room temperature in vacuo. To remove homopolymer from the grafting product, the preduct was extracted with benzene in a soxhlet extractor for at least $20 \mathrm{hr}$ until no further extraction was noted. The residue from the extraction is considered as the graft polymer and total conversion $(T C)$, percent grafting $(G)$ and grafting efficiency $(G E)$ were calculated as follows:

$$
\begin{aligned}
& T C=\frac{\text { weight of polymer }}{\text { weight of monomer }} \times 100 \\
& G=\frac{\text { weight of grafted polymer }}{\text { weight of cellulose backbone }} \times 100 \\
& G E=\frac{\text { weight of grafted polymer }}{\begin{array}{c}
\text { weight of grafted polymer }+ \\
\text { weight of homopolymer }
\end{array}} \times 100
\end{aligned}
$$

\section{Isolation of Grafted Chain ${ }^{7}$}

The graft copolymer $(1 \mathrm{~g})$ was dissolved in
$72-\%$ sulfuric acid $(40 \mathrm{ml})$, the solution was diluted with water $(1.5 l)$ and boiled at $100^{\circ} \mathrm{C}$ for $40 \mathrm{~min}$. The separated copolymer was purified by disolving in benzene and precipitating with methanol.

\section{RESULTS AND DISCUSSION}

\section{Cellulosic Materials}

As shown in Table I, when cotton linter was treated with periodate, the hydroxyl groups of

Table I. Cellulosic materials containing carbonyl

\begin{tabular}{|c|c|c|c|c|c|c|}
\hline \multirow{2}{*}{$\begin{array}{c}\text { Sample } \\
\text { Oxi- } \\
\text { dation } \\
\text { time } \\
\text { with } \\
\mathrm{HIO}_{4} \text {, } \\
\text { hr }\end{array}$} & \multicolumn{2}{|c|}{$\mathrm{HIO}_{4}$} & \multicolumn{2}{|c|}{$\underset{\mathrm{NaClO}_{2}}{\mathrm{HIO}_{4}-}$} & \multicolumn{2}{|c|}{$\underset{\mathrm{NaBH}_{4}}{\mathrm{HIO}_{4}-}$} \\
\hline & $\begin{array}{c}\mathrm{CO} \\
\mathrm{mm}\end{array}$ & $\begin{array}{l}\mathrm{COOH}, \\
\mathrm{hol} / 100 \mathrm{~g}\end{array}$ & $\begin{array}{l}\mathrm{CO} \\
\mathrm{mm}\end{array}$ & $\begin{array}{l}\mathrm{COOH} \\
\mathrm{l} / 100 \mathrm{~g}\end{array}$ & $\begin{array}{l}\mathrm{CO} \\
\mathrm{mmc}\end{array}$ & $\begin{array}{l}\mathrm{COOH}, \\
\mathrm{ol} / 100 \mathrm{~g}\end{array}$ \\
\hline 0.5 & 10.5 & 0 & 1.2 & 15.6 & 2.8 & 0 \\
\hline 1 & 15.6 & 0 & 2.4 & 22.7 & 4.3 & 0 \\
\hline 3 & 40.1 & 0 & 6.0 & 46.2 & 6.1 & 0 \\
\hline 8 & 70.5 & 0 & 11.2 & 82.1 & 2.4 & 0 \\
\hline
\end{tabular}
and carboxyl groups used for graft

copolymerization

$C(2)$ and $C(3)$ in the cellulose chains were oxidized to dialdehyde groups. ${ }^{8}$ When periodateoxidized celluloses were treated with sodium chlorous acid or sodium borohydride, the carbonyl groups were converted to carboxyl or hydroxyl groups, respectively.

Graft Copolymerization of Styrene on to Cellulosic Materials Effect of Ceric Salt Concentration. Craft copolymerizations were carried out in the presence of cellulosic materials such as $\mathrm{H}, \mathrm{H}-\mathrm{Na}$ and $\mathrm{H}-\mathrm{B}$ samples with varying concentrations of initiator at $60^{\circ} \mathrm{C}$ for $1.5 \mathrm{hr}$.

As shown in Figure 1, styrene was grafted only on to the $\mathrm{H}$-sample in the aqueous medium, whereas in a 50-\% ethanol medium it was also grafted to a small extent on to the $\mathrm{H}-\mathrm{Na}$ and $\mathrm{H}-\mathrm{B}$ samples. The percent grafting reached to a maximum or a levelling-off value at a ceric salt concentration of approximately $10-20 \mathrm{mmol} /$ l. On the other hand, the grafting efficiency decreased with the concentration of ceric salt.

Effect of Ethanol Concentration. Graft copolymerization of $\mathrm{St}$ on to the $\mathrm{H}$-sample (CO groups $70.5 \mathrm{mmol} / 100-\mathrm{g}$ cellulose) was carried out at 


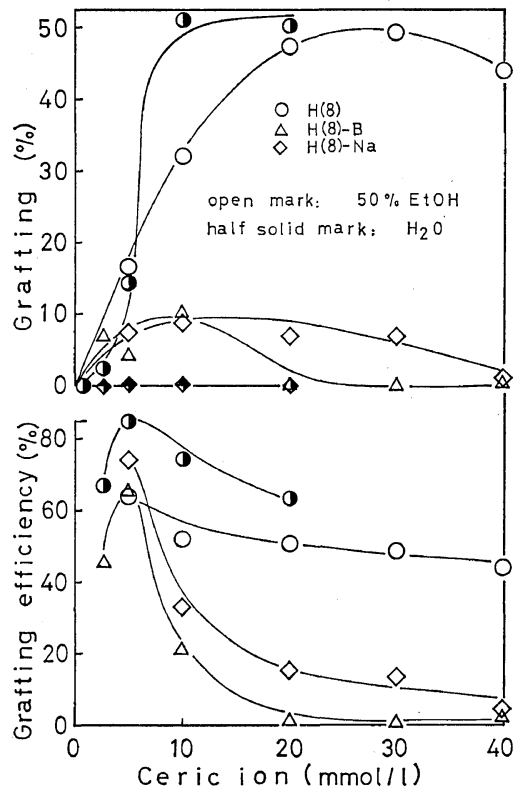

Figure 1. Effect of concentration of ceric salt on percent grafting (top) and grafting efficiency (bottom) in the grafting of St to cellulosic materials: [M] $0.871 \mathrm{~mol} / l ; 60^{\circ} \mathrm{C}, 1.5 \mathrm{hr}$.

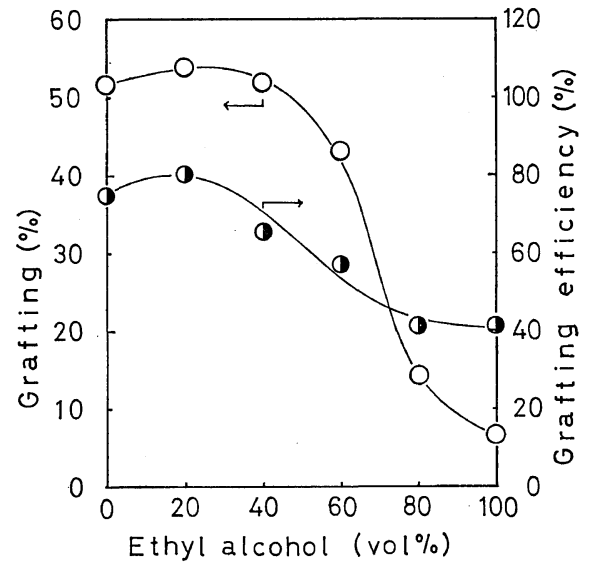

Figure 2. Effect of the concentration of ethanol in the polymerization medium on percent grafting and grafting efficiency in the grafting of St to $\mathrm{H}$ sample (CO groups $70.5 \mathrm{mmol} / 100 \mathrm{~g}$ cellulose): $[\mathrm{Ce}], 10 \mathrm{mmol} / l,[\mathrm{M}], 0.871 \mathrm{~mol} / l ; 60^{\circ} \mathrm{C}, 1.5 \mathrm{hr}$.

various concentrations of ethanol at $60^{\circ} \mathrm{C}$ for $1.5 \mathrm{hr}$.

As shown in Figure 2, the percent grafting and the grafting efficiency in the ethanol concentration of $0-40 \%$ remained almost constant at the values of $55 \%$ and $75 \%$, respectively. They decreased rapidly at concentrations higher than $40 \%$. This indicates that no chain transfer to ethanol occured. From these results, the subsequent graft copolymerizations were carried out in $40-\%$ ethanol medium with $10 \mathrm{mmol} / \mathrm{l}$ of ceric salt.

Effect of Styrene Concentration. Graft copolymerizations of St on to cellulosic materials were carried out using various monomer concentrations at $60^{\circ} \mathrm{C}$ for $2 \mathrm{hr}$.

As shown in Figure 3, the total conversion

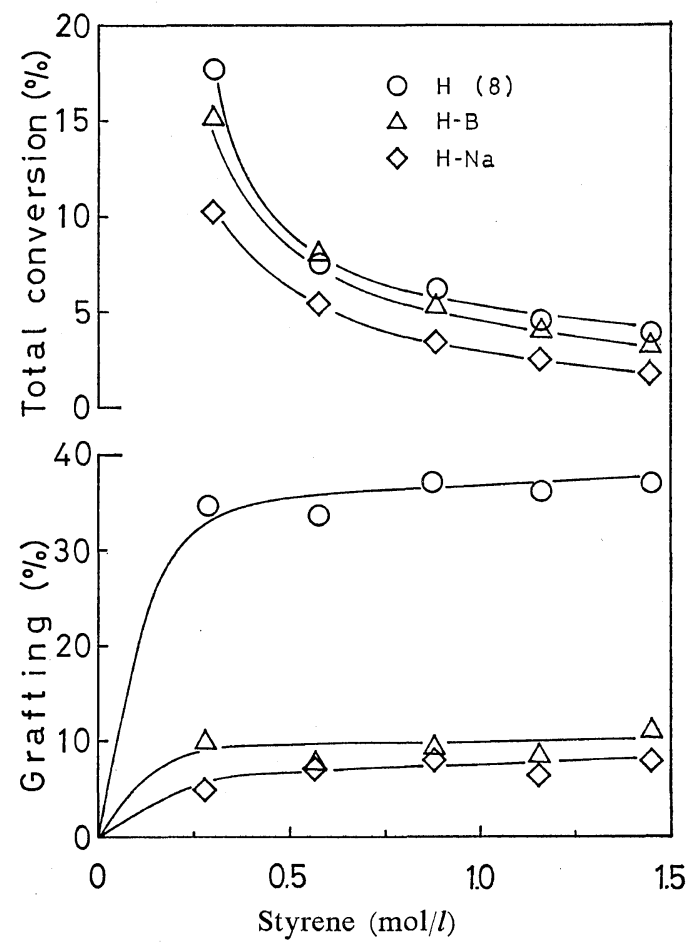

Figure 3. Effect of monomer concentration on the grafting of $\mathrm{St}$ to cellulosic materials: [Ce], $10 \mathrm{mmol} / \mathrm{l}, 40 \% \mathrm{EtOH}, 60^{\circ} \mathrm{C}, 1.5 \mathrm{hr}$.

decreases rapidly with the monomer concentration. These features have not been previously observed in the polymerization of $\mathrm{MMA}^{4}$ and acrylamide ${ }^{9}$ in an aqueous medium. These results suggest that propagation of St did not occur easily for the polymerization in EtOH medium. On the other hand, the percent grafting reached a constant value with the monomer concentration of $0.3 \mathrm{~mol} / \mathrm{l}$. 


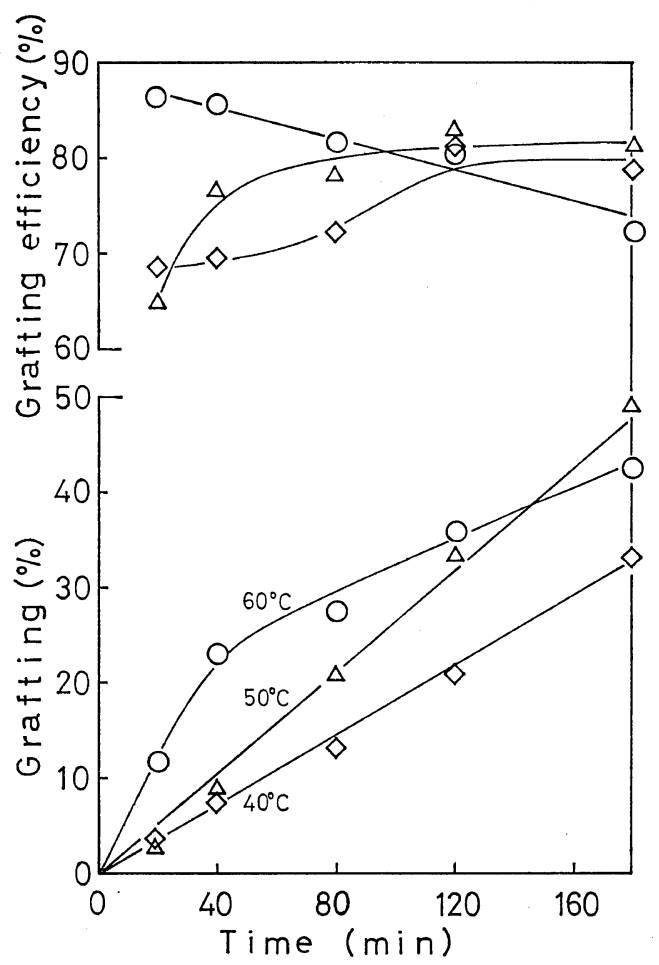

Figure 4. Effect of the grafting time and temperature on percent grafting and grafting efficiency in the grafting of $\mathrm{St}$ to $\mathrm{H}$ sample ( $\mathrm{CO}$ groups $70.5 \mathrm{mmol} / 100 \mathrm{~g}$ cellulose): [Ce], $10 \mathrm{mmol} / l ;$ [M], $0.871 \mathrm{~mol} / \mathrm{l} ; 40 \%$ EtOH.

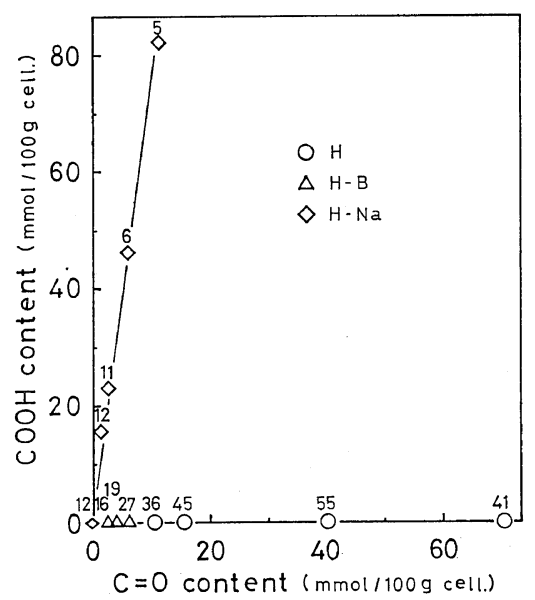

Figure 5. Effect of functional groups in the grafting of St to cellulosic materials. The number is the percent grafting: [Ce], $10 \mathrm{mmol} / l ;[\mathrm{M}], 0.871$ $\mathrm{mol} / \mathrm{l} ; 40 \% \mathrm{EtOH}, 50^{\circ} \mathrm{C}, 3 \mathrm{hr}$.
Effect of Temperature. Figure 4 shows the effect of the temperature on the rate of the graft copolymerization on to the $\mathrm{H}$-sample.

The initial rate of the graft copolymerization increases with time and temperature of polymerization. The grafting effeciency at $40^{\circ} \mathrm{C}$ and $50^{\circ} \mathrm{C}$ increases with the reaction time, but decreases at $60^{\circ} \mathrm{C}$. The apparent rate of the graft copolymerization as a function of the reciprocal of the absolute temperature was shown to be a straight line. The apparent activation energy obtained from these results was approximately $14.2 \mathrm{kcal} /$ mol. This value is smaller than those found for other radical polymerizations.

Effects of Varying Content of Carbonyl and Carboxyl Groups. The effects of the amount of functional groups on percent grafting is shown in Figure 5.

As shown in Figure 5, the percent grafting increases with the carbonyl group content, but decreases with carboxyl group content. The same result was obtained in the graft copolymerization of acrylamide. ${ }^{9}$ It is suggested that the carbonyl group exerts some effect on the redox reaction (initiation) between the ceric salt and the hydroxyl groups in cellulose molecules, and that the catalyst activity is decreased due to the reaction between the carboxyl group and the ceric salt.

Graft Copolymerization of Methyl Methacrylate+ Styrene on to Cellulosic Materials

Yield of Polymerization. Graft copolymerization of MMA +St on to cellulosic materials was carried out in $40-\%$ ethanol medium at $60^{\circ} \mathrm{C}$ for $1.5 \mathrm{hr}$. The effect of the monomer composition in the feed on the yield of polymerization was studied.

As shown in Figure 6, both total conversion and percent grafting increase with the MMA content in the feed. A similar experiment was carried out in the absence of cellulose. From these results, it was deduced that the polymerization rate is greatly enhanced by the presence of cellulosic materials and that the percent grafting on to the $\mathrm{H}$ sample was larger than that on to C-sample.

Alternating Tendency in Copolymerization. The copolymer composition was determined by elemental analysis. 
Graft Copolymerization onto Oxidized Cellulose

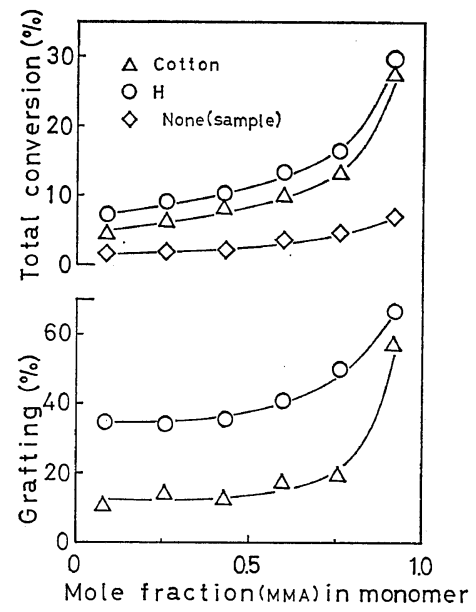

Figure 6. Effect of the feed composition on total conversion and percent grafting in the grafting of St+MMA to cellulosic materials: [Ce], $10 \mathrm{mmol} /$ l; $40 \% \mathrm{EtOH}, 60^{\circ} \mathrm{C}, 1.5 \mathrm{hr}$.

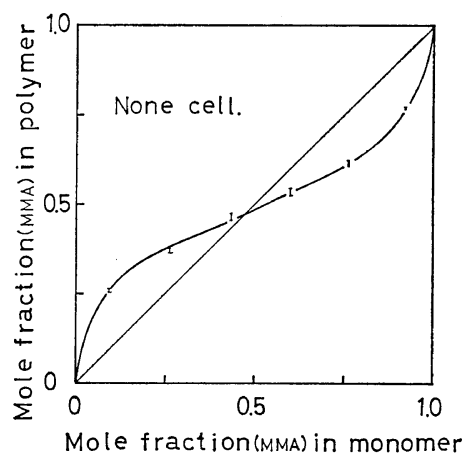

Figure 7. Composition curve of copolymer in the copolymerization of $\mathrm{St}+\mathrm{MMA}$ in absence of cellulosic materials: [Ce], $10 \mathrm{mmol} / l ; 40 \% \mathrm{EtOH}$, $60^{\circ} \mathrm{C}, 1.5 \mathrm{hr}$.

Figures 7,8 , and 9 show the composition curves for the copolymerizations of $\mathrm{MMA}+\mathrm{St}$ either in absence of cellulosic material or in presence of $\mathrm{C}$ and $\mathrm{H}$ samples, respectively. From these results, it is evident that the copolymerization of these monomers proceeds by a free radical mechanism.

The monomer reactivity ratios $r_{1}$ (MMA) and $r_{2}$ (St) obtained by using the Fineman-Ross method (Figure 10) are as follows.

Grafted copolymer:

$$
r_{1}=0.22, r_{2}=0.69, r_{1} \times r_{2}=0.15 \pm 0.02
$$

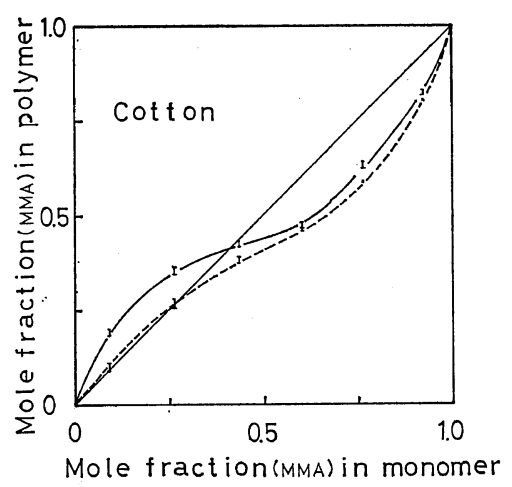

Figure 8. Composition curves of copolymer in the copolymerization of St+MMA in presence of cotton linter: - , ungrafted copolymer, --, grafted copolymer; $[\mathrm{Ce}], 10 \mathrm{mmol} / l ; 40 \% \mathrm{EtOH}, 60^{\circ} \mathrm{C}$, $1.5 \mathrm{hr}$.

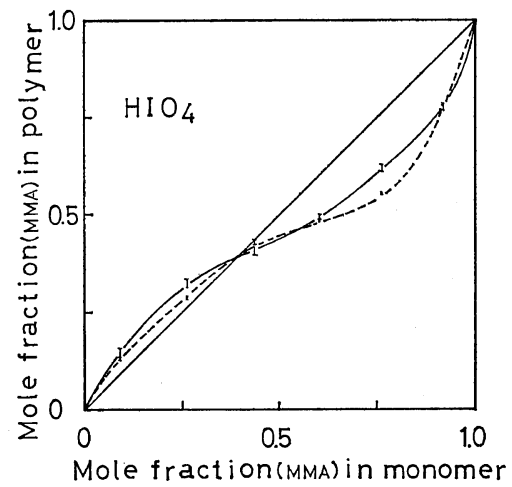

Figure 9. Composition curves of copolymer in the copolymerization of St+MMA in presence of $\mathrm{H}$ sample (CO groups $70.5 \mathrm{mmol} / 100 \mathrm{~g}$ cellulose): -, ungrafted copolymer; ---, grafted copolymer; [Ce], $10 \mathrm{mmol} / l ; 40 \% \mathrm{EtOH}, 60^{\circ} \mathrm{C}, 1.5 \mathrm{hr}$.

in presence of $\mathrm{C}$ sample, $r_{1}=0.17, r_{2}=0.57, r_{1} \times r_{2}=0.10 \pm 0.00$

in presence of $\mathrm{H}$ sample.

Ungrafted copolymer:

$r_{1}=0.06, r_{2}=0.32, r_{1} \times r_{2}=0.02 \pm 0.01$

in presence of $\mathrm{C}$ sample,

$r_{1}=0.17, r_{2}=0.47, r_{1} \times r_{2}=0.08 \pm 0.00$

in presence of $\mathrm{H}$ sample,

$r_{1}=0.24, r_{2}=0.28, r_{1} \times r_{2}=0.07 \pm 0.00$

in absence of cellulosic materials.

In free radical polymerization, the range of 


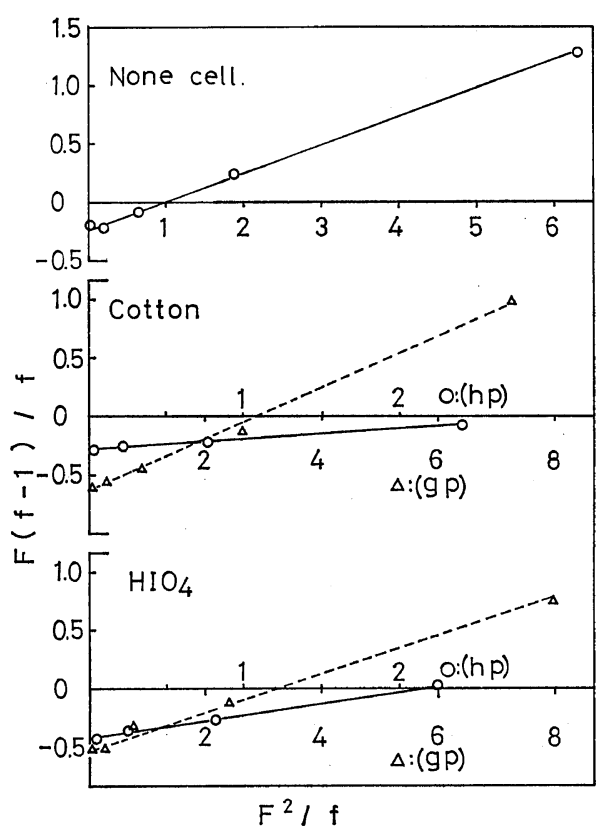

Figuer 10. Fineman-Ross plots of copolymer in the copolymerization of St+MMA either in absence or in presence of cellulosic materials: -, ungrafted copolymer; ---, grafted copolymer.

$r_{1} \times r_{2}$ values is $0<r_{1} \times r_{2}<1$ and the alternating tendency of copolymer increases with decreasing $r_{1} \times r_{2}$. Thus it is conceivable that, in grafting on to the $\mathrm{C}$ sample, the alternating tendency of the ungrafted copolymer is higher than that of the grafted one. This is deduced from the result that the composition curves of the ungrafted copolymer treated with sulfuric acid coincide with those of untreated copolymer (Figure 7). The alternating tendency of the copolymer obtained by copolymerization in the absence of cellulosic materials is also higher than that of graft copolymer.

From these results, it is considerd that the monomer reactivity ratios in the presence of cellulosic materials are different to those in the absence of cellulosic materials due to the interaction between the cellulosic material and the monomers. It is found in this experiment that the values of $r_{1}$ and $r_{2}$ of ungrafted copolymer obtained by the copolymerization in heterogeneous system is smaller than that of the copolymer, ${ }^{10}$ which have been obtained by the bulk method. ${ }^{11}$

\section{REFERENCES}

1. T. Toda, J. Polym. Sci., 58, 411 (1962).

2. Y. Ogiwara, Y. Ogiwara, and H. Kubota, ibid., 5, 2791 (1967).

3. H. A. Rutherford and P. W. Minor, J. Res. Nat. Bur. Stand., 29, 131 (1942).

4. A. Takahashi and S. Takahashi, Kogyo Kagaku Zasshi (J. Chem. Soc. Japan, Ind. Chem. Sect.), 74, 2541 (1971).

5. G. F. Davidson and T. P. Nevell, J. Textile Inst., 39, $\mathrm{T} 102$ (1948).

6. S. Watanabe and K. Kuwana, J. Tech. Assocn. Pulp and Paper Ind. (Japan) 10, 524 (1956).

7. F. Ide, Kogyo Kagaku Zasshi (J. Chem. Soc., Japan, Ind. Chem. Sect.), 64, 1489 (1961).

8. G. F. Davidson, J. Textile Inst., 31, T81 (1940).

9. A. Takahashi and S. Takahashi, Kobunshi Kagaku (Chem. High Polymers), 30, 239 (1973).

10. A. Takahashi and S. Takahashi, Sen-i Gakkaishi (J. Soc. Textile Cellulose Ind. Japan), 30, T347 (1974).

11. L. Walling, W. Cummings, E. Briggs, and F. Mayo, J. Amer. Chem. Soc., 70, 1527 (1948). 